\title{
BMJ Open Protocol for establishing an infant feeding database linkable with population-based administrative data: a prospective cohort study in Manitoba, Canada
}

Nathan Christopher Nickel, ${ }^{1,2}$ Lynne Warda, ${ }^{3,4}$ Leslie Kummer, ${ }^{5}$ Joanne Chateau, ${ }^{1}$ Maureen Heaman, ${ }^{6}$ Chris Green, ${ }^{1,7}$ Alan Katz, ${ }^{1,2,8}$ Julia Paul, ${ }^{9}$ Carolyn Perchuk, ${ }^{7}$ Darlene Girard, ${ }^{7}$ Lorraine Larocque, ${ }^{10}$ Jennifer Emily Enns, ${ }^{1,2}$ Souradet Shaw, ${ }^{11}$ The Manitoba Infant Feeding Database Development Team

To cite: Nickel NC, Warda L, Kummer L, et al. Protocol for establishing an infant feeding database linkable with population-based administrative data: a prospective cohort study in Manitoba, Canada. BMJ Open 2017;7:e017981. doi:10.1136/ bmjopen-2017-017981

- Prepublication history and additional material for this paper are available online. To view please visit the journal (http:// dx.doi.org/10.1136/bmjopen2017-017981).

Received 30 May 2017 Revised 11 September 2017 Accepted 12 September 2017

CrossMark

For numbered affiliations see end of article.

\section{Correspondence to} Dr Nathan Christopher Nickel; Nathan_Nickel@cpe.umanitoba. ca

\section{ABSTRACT}

Introduction Breast feeding is associated with many health benefits for mothers and infants. But despite extensive public health efforts to promote breast feeding, many mothers do not achieve their own breastfeeding goals; and, inequities in breastfeeding rates persist between high and low-income mother-infant dyads. Developing targeted programme to support breastfeeding dyads and reduce inequities between mothers of different socioeconomic status are a priority for public health practitioners and health policy decision-makers; however, many jurisdictions lack the timely and comprehensive population-level data on infant-feeding practices required to monitor trends in breastfeeding initiation and duration. This protocol describes the establishment of a populationbased infant-feeding database in the Canadian province of Manitoba, providing opportunities to develop and evaluate breastfeeding support programme.

Methods and analysis Routinely collected administrative health data on mothers' infant-feeding practices will be captured during regular vaccination visits using the Teleform fax tool, which converts handwritten information to an electronic format. The infant-feeding data will be linked to the Manitoba Population Research Data Repository, a comprehensive collection of populationbased information spanning health, education and social services domains. The linkage will allow us to answer research questions about infant-feeding practices and to evaluate how effective current initiatives promoting breast feeding are.

Ethics and dissemination Approvals have been granted by the Health Research Ethics Board at the University of Manitoba. Our integrative knowledge translation approach will involve disseminating findings through government and community briefings, presenting at academic conferences and publishing in scientific journals.

\section{INTRODUCTION}

Breast feeding is associated with numerous health benefits for mothers and their

\section{Strengths and limitations of this study}

- This study is among the first to establish a mechanism for collecting infant-feeding data at a population level in Canada, providing longitudinal data to study the impact of policy, programme and services on infant-feeding practices.

- Our ability to link the infant-feeding database with a large repository of administrative data spanning several domains increases the number of confounding characteristics we can adjust for in our analyses.

- Using linked whole population data means there will be minimal loss to follow-up and allows us to compare individuals captured in the infant-feeding database with individuals who were not.

- Using vaccination visits as the point of contact for data collection means some individuals will be missed (although more than $90 \%$ of infants receive the recommended vaccinations at 2 months of age).

- Collecting data on infant feeding routinely relies on maternal report, which can be subject to social desirability bias.

infants. $^{1-7}$ The WHO, Unicef and other health authorities recommend exclusive breast feeding for the first 6 months of life, followed by continued feeding of breast milk along with complementary foods for 2 years and beyond. ${ }^{8-12}$ However, in spite of extensive public health efforts to support breast feeding, two challenges remain: (1) many mothers do not achieve their own breastfeeding goals and (2) inequities in breastfeeding outcomes persist between mother-baby dyads living in marginalised circumstances and their more advantaged counterparts. ${ }^{13-15}$ Findings from the Canadian Maternity Experiences Survey showed 
that although breastfeeding initiation rates were relatively high in Canada, exclusive breastfeeding duration fell short of globally recommended standards, with only $14.4 \%$ of mother-baby dyads breast feeding exclusively at 6 months after birth. ${ }^{16}$ Based on these figures, developing targeted programme and interventions to support breastfeeding dyads and reduce breastfeeding inequities have become a priority for public health practitioners and health policy decision-makers. ${ }^{17} 18$ However, many jurisdictions lack the timely and comprehensive population-level data on infant-feeding practices required to monitor trends in breastfeeding initiation and duration.

\section{Current state of infant-feeding surveillance}

In North America, much of the data on infant-feeding practices are collected through primary data collection methods such as cross-sectional surveys and cohort studies. Most global surveillance of longitudinal infant feeding is accomplished through periodic surveys of populations, often at the time of hospital discharge or in the postpartum period. ${ }^{19-22}$ These methods of epidemiological surveillance have some important limitations ${ }^{23-27}$ :

1. Significant resources are required to design and implement novel high-quality cohort studies;

2. Families living in disadvantaged social and economic circumstances-such as low-income households and families with high residential mobility—may be under-represented in survey research;

3. Lack of whole population data makes generalisability challenging and limits planners' ability to conduct small area-level analyses;

4. Relying on survey data collected for a single purpose makes it difficult to track outcomes across the life span.

In light of these and other limitations, researchers are turning to routinely collected administrative health data to conduct a wide variety of epidemiological research studies. ${ }^{27}$

\section{How can administrative health and social data help address evidence gaps?}

Contacts with the health and social services systems generate data in the form of administrative records. Linking these routinely collected records across sectors is a powerful tool for conducting large-scale, longitudinal epidemiological research. ${ }^{23-25}$ For example, researchers in Europe and Australia have been using linked administrative health data to monitor breastfeeding initiation and duration rates for the last two decades. ${ }^{29-32}$ In Canada, studies have used breastfeeding initiation data obtained from the birth hospital discharge abstracts to track trends and inequities in breastfeeding initiation and examine outcomes associated with initiating breast feeding during the first days of life. ${ }^{133}$ Although providers routinely ask questions about infant-feeding practices during well-baby visits throughout the first year of life, including questions about breastfeeding duration, this information is seldom integrated into a centralised database. Thus, researchers and programme planners lack comprehensive data on infant-feeding practices once the mother-baby dyad is discharged from the birth hospital stay. Therefore, there is a critical need to identify a mechanism whereby infantfeeding information that is routinely collected during well-baby visits can be consolidated in a whole population database.

\section{Research objective}

The objective of this work is to establish a mechanism for collecting infant-feeding information during routine contacts with the healthcare system, which can then be linked with a centralised data repository of administrative health data. Specifically, it will evaluate whether a Teleform fax system is a viable mechanism for (1) collecting infant-feeding data when infants receive their 2, 4 and 6-month vaccinations and (2) automatically depositing that information into the new Manitoba Infant Feeding Database (MIFD) and linking it at the individual level with the Manitoba Population Research Data Repository, an established repository of administrative health and social data.

We will address the following research questions:

1. What per cent of data collected using the Teleform have transcription errors when automatically read into an electronic format, requiring manual verification and edits?

2. What are the patterns of missing data in the Manitoba Infant Feeding Database?

3. What per cent of infants are captured at the 2, 4 and 6-month vaccination visits?

4. Do data capture rates differ by rural/urban status of the study sites?

5. What maternal characteristics (maternal age, income, residential mobility) and infant characteristics (sex, small for gestational age, large for gestational age, Apgar score) are associated with data captured at the 2,4 and 6 -month vaccination visits?

\section{METHODS AND ANALYSIS \\ Setting}

The study funding period began in October 2014 and ends in August 2018. The study takes place in Manitoba, a central Canadian province with approximately 1.3 million residents. For the past 4 years, the annual number of births in the province has ranged between 15000 and 17000 births. Just over $80 \%$ of mother-infant dyads initiate breast feeding during the birth hospital stay; however, initiation rates follow a socioeconomic gradient where low-income dyads are less likely to initiate breast feeding compared with their higher income counterparts. ${ }^{13-15}$

A unique and advantageous feature of establishing an infant-feeding database in Manitoba is our ability to link the new Manitoba Infant Feeding Database to the established Manitoba Population Research Data Repository. ${ }^{34} 35$ The Repository contains more than 30 years of population-based, individual-level information on all 
Manitobans who are registered with the province of Manitoba's universal health insurance programme; thus, the Repository contains information on $99.9 \%$ of Manitobans residents. Each time a Manitoba resident is in contact with the healthcare system, the information from that contact is recorded and held in the repository. The repository data are deidentified using strict protocols to preserve residents' anonymity but can be linked longitudinally and across sectors using a scrambled personal identification number. ${ }^{2325}{ }^{27}$ Besides health information, the repository includes administrative records from social services and government programme, children's education records and contacts with the criminal justice system. ${ }^{23} 25$ The repository data have been validated and used extensively for maternal and child health research studies. ${ }^{36-40}$

\section{Identifying opportunities for data collection at routine vaccination visits}

We began by identifying infant vaccination visits as a consistent and opportune routine point of contact with the healthcare system, whereby population-based information on infant feeding could be collected. In Manitoba, more than $90 \%$ of infants complete their 2-month vaccination schedules and $78 \%$ complete their 1 year vaccination schedules. ${ }^{41}$ Thus, using this point of contact, infant-feeding information could be collected from nearly every mother-baby dyad in the province. With consideration for the funding timeline, we selected the 2, 4 and 6-month vaccination visits as infant-feeding data collection time points.

\section{Selecting and optimising a tool for data collection: the teleform fax tool}

It was important to choose a tool that falls within the requirements of the personal health information legislation in Manitoba and that could be widely applied across the province. Manitoba does not currently have an online system that complies with privacy legislation for personal health information sharing; online data collection and sharing would also not be feasible in many of Manitoba's rural and remote communities where internet connectivity is poor or non-existent. We selected the Teleform Fax Tool ${ }^{42}$ since it is compliant with Manitoba's personal health information legislation and can be used without internet access. Fax technology is also routinely used to collect health information in jurisdictions across Canada, ${ }^{43-46}$ and as such, is an accepted tool for collecting survey data.

To place a minimum burden on mothers and healthcare workers, ensure that the Teleform questions could be answered quickly and easily and maximise the possibility that such a system could be routinely implemented across the province, we conducted a literature search to identify a short set of questions that would yield rich data on infant-feeding practices posthospital discharge ${ }^{47}$ During the summer of 2015, we piloted a draft version of the questions (box) by conducting three focus groups with new mothers: one urban group comprising 8 mothers,
Box Infant Feeding Questions Pilot Tested with Manitoba Mothers

1. What has your baby been fed since birth?

a. Only Breastmilk. (End of questions)

b. Only formula/other food. (End of questions)

c. Breastmilk and formula/other food. (Go to question 2)

2. During the past week, what did you feed your baby?

a. Breastmilk only. (Go to question 3)

b. Breastmilk and formula/other food. (Go to question 4)

c. Only formula/other food. (Go to question 5)

3. Was your baby only supplemented in the hospital?

a. Yes, my baby was only supplemented in the hospital. Otherwise I have only breastfed (End of questions)

b. No, my baby was supplemented in the hospital and at home. (Go to question 4)

4. How many weeks old was your baby when you first fed formula/ other food?

5. How many weeks old was your baby when you completely stopped breastfeeding?

one group of 9 mothers in a rural agricultural community and one group of 12 mothers from a remote rural community.

During the focus groups, the mothers each answered the questions on infant-feeding practices and then discussed as a group how they interpreted each question. They provided feedback on question structure and order to improve the clarity of questions and reduce response burden. The final set of questions included in the Teleform to measure infant-feeding practices were selected based on the focus group feedback; these are based on questions used in other prospective studies that follow mother-infant dyads from birth through the first year of life, aimed at measuring breastfeeding duration. ${ }^{48} 49$ As well, these questions will capture data that will allow us to construct variables on infant feeding in alignment with the WHO's definitions of breast feeding. ${ }^{50-53}$

Our questions ask mothers to report duration of exclusive breast feeding and complementary breastfeeding. Research has shown maternal recall of breastfeeding duration is high when the recall period is less than 1 year. ${ }^{54}$ The Teleform does not rely exclusively on 24 hours recall to measure infant-feeding practices since some studies have shown that 24 hours recall may overestimate prevalence of exclusive breast feeding and thus recommend that infant feeding be prospectively measured with a combination of current status and recall since birth. ${ }^{55-60}$

The Teleform also collects data for linkage purposes, including: (1) the mother's and infant's personal health identification numbers (PHINs; unique, person-level identifiers held in the repository); (2) the infant's birth date; (3) the infant's sex and (4) the mother's postal code. The final version of the Teleform is presented in see online supplementary file 1 . 


\section{Recruitment and data collection}

Recruitment and data collection began in September 2015 and will continue until December 2017. Six study sites are enrolled: one urban clinic where $75 \%$ of all urban-dwelling children in Manitoba receive their vaccinations, two rural public health offices located in agricultural communities and three rural public health offices located in rural remote settings. Over the past 3 years, the annual number of children vaccinated across all six sites ranged between 1500 and 2000 children.

Mothers who bring their infants to study site clinics for vaccination visits are asked by clinic staff members to participate in the study. Clinic staff provide them with documents describing the study and its purpose, along with informed consent documentation. Mothers who review the documents and give written informed consent are enrolled in the study. Study participants are asked to complete the Teleform at their infants' 2, 4 and 6-month vaccination visits. Mothers fill out the Teleform during the visit and then return it to staff before leaving the clinic. Data collected with the Teleform are faxed by the clinic staff to the research study office located within a government agency. There, the data are automatically extracted from the faxed form and an image of the form is placed on a password-protected network in a secure data environment with restricted card access. Data quality checks are run manually to identify transcription errors and missing data. For each data field, we are documenting the percentage with transcription errors, requiring manual verification and needing manual edits to address research question 1 .

Table 1 presents preliminary summary enrolment figures and vaccination rates of infants at each study site (September 2015 to December 2016). During this period, approximately $75 \%$ of mothers consented to provide feeding data for the study. At the end of the data collection phase, we will conduct descriptive summary statistics to identify patterns of transcription errors and missing data to answer our first two research questions.

\section{Linking infant-feeding data with the Manitoba population research data repository}

The MIFD is composed of two datasets: (1) the Infant Feeding Dataset consisting of infant-feeding data and individuals' unique study identification (ID) and (2) the Identifying Dataset comprising mothers' and infants' PHINs, infant's date of birth, infant's sex, mother's postal code and infant's unique study ID. Table 2 depicts the information held in the two datasets. Figure 1 shows the data flow process from point of data collection to acquisition into the Manitoba Population Research Data Repository for data analyses.

The MIFD will be held in and linked to the Manitoba Population Research Data Repository. The Repository is a collection of over 70 databases containing information on health, education, receipt of social services and interactions with the justice system. The Manitoba Health Insurance Registry includes individuals' unique scrambled

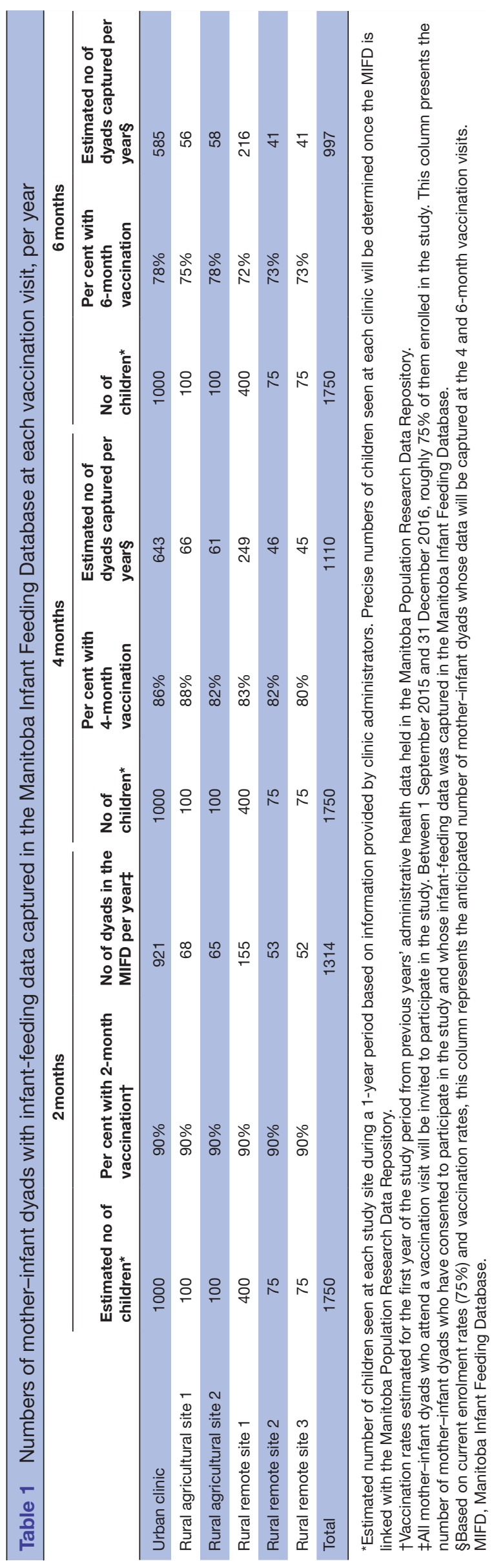


Table 2 Datasets in the Manitoba Infant Feeding Database

\begin{tabular}{ll}
\hline Infant-feeding dataset & Identifying dataset \\
\hline Unique study ID & Unique study ID \\
Infant feeding status at & Mother's PHIN \\
vaccination visit & Infant's PHIN \\
Infant age at cessation of & Infant's birth date \\
exclusive breastfeeding & Mother's postal code \\
Infant age at cessation of & \\
breastfeeding & \\
Whether infant was & \\
supplemented during hospital & \\
stay &
\end{tabular}

ID, identification; PHIN, personal health identification number.

PHINs and a family registration number, which allows linkages between mothers and their infants. Using scrambled PHINs and cross-walk files generated by Manitoba Health, individual-level data can be linked across all datasets held in the repository in a deidentified way.

\section{Study cohort development}

We will construct the study cohort using the whole population data held in the repository. The cross-walk file generated by Manitoba Health will be used to link mothers and infants and to link infants' feeding data with their health records in the repository. Specifically, infant-feeding data will be linked with the following administrative health data: (1) the dyad's birth hospital discharge data, (2) the infant's vaccination records held in the Manitoba Immunisation Monitoring System, (3) medical billing records associated with the infant's primary care visits held in the Medical Services dataset and (4) the mother's postal code of residence held in the Manitoba Health Insurance Registry. The cohort will include all mothers and infants who had at least one vaccination visit at one of the study sites between 1 September 2015 and 31 December 2017; thus it, will include infants with and without feeding data. For those without feeding data, the relevant data fields in the Manitoba Infant Feeding Database will read 'missing'. We will use multivariable logistic regression models to identify characteristics associated with having missing data in the MIFD.

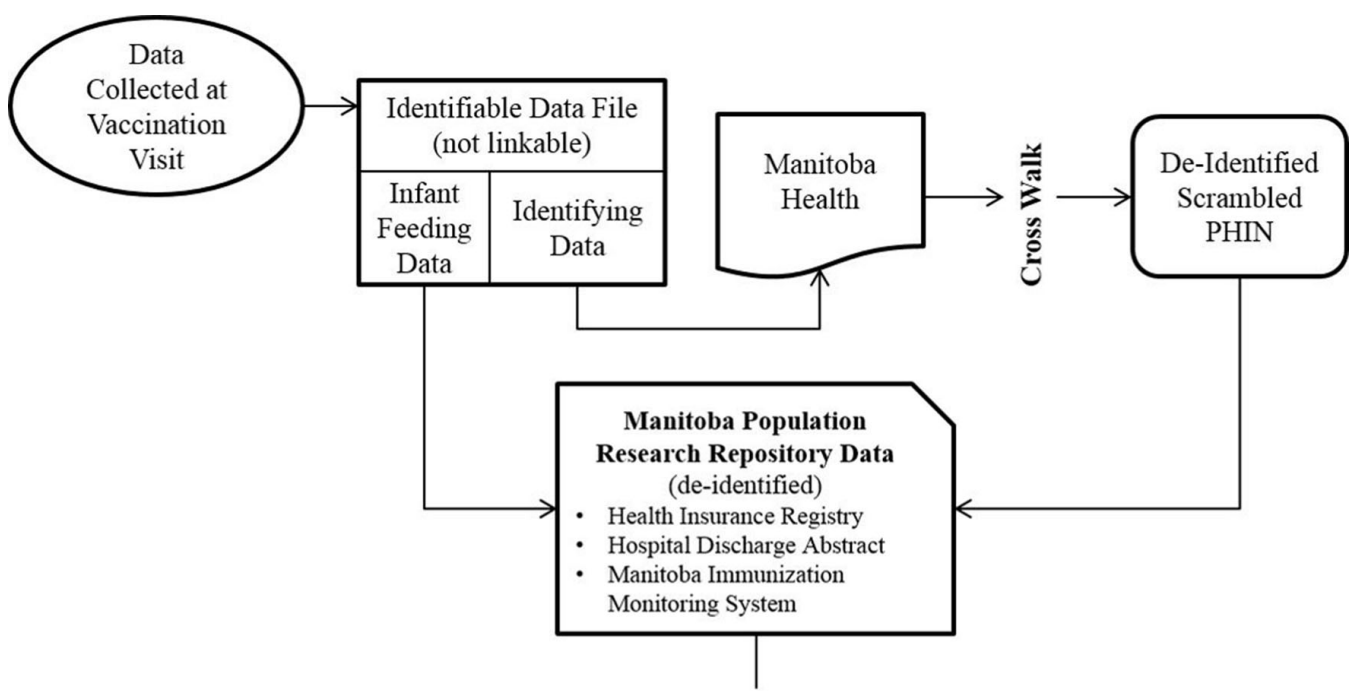

Cross Walk and Scrambled PHIN

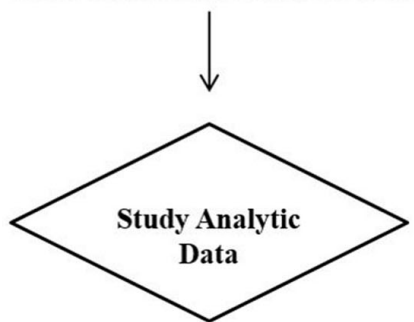

Figure 1 Manitoba Infant Feeding Database data flow diagram. ID, identification; PHIN, Personal Health Identification Number. Data are collected at vaccination visits using the Teleform and faxed to a central office. The identifiable data file contains two datasets: (1) Infant Feeding Data (a dataset that includes infant-feeding information and study ID) and (2) Identifying Data (a dataset that includes identifying information and study ID). The Identifying Data are sent to Manitoba Health for deidentification and attachment of scrambled PHIN. Manitoba Health generates a cross-walk file with instructions for data Inkage. The Infant Feeding Data are sent to the Manitoba Population Research Data Repository. The Scrambled PHIN, study ID and cross-walk file are used to link infant-feeding data with the rest of the administrative data held in the repository. The linked databases form the analytical data for the study. 


\section{Variable construction}

Using the study cohort, we will develop variables to address research questions 3-5. Table 3 presents each of the outcome variables we will examine in these analyses. Because the data include all contacts with the healthcare system, we will be able to follow infants as they access healthcare services across the province; we will be able to track all vaccinations for infants in the study, regardless of whether or not that vaccination was given at one of the study sites. We will construct a set of three variablesone for each vaccination visit-to describe whether we captured infant feeding data from the dyad. For each visit, the variable will tell us (1) if feeding data were recorded, (2) if a vaccination visit was recorded at a study site but feeding data are missing, (3) if a vaccination visit was recorded at a non-study site and (4) whether an infant has a vaccination recorded for that time point.

A feeding history for each infant will be constructed using data from the hospital discharge abstract and feeding data collected at each vaccination visit. The feeding history will indicate whether an infant is exclusively breast feeding, complementary breast feeding or exclusively formula feeding at four contacts with the healthcare system: birth hospital discharge, 2, 4 and 6-month vaccination visits (definitions presented in table 2). We use the WHO definitions for infant-feeding status at each time point:

- Exclusive breast feeding-an infant is only fed breast milk (including milk expressed or from a wet nurse) and not fed anything else and

- Complementary Feeding — an infant is fed breast milk (including milk expressed or from a wet nurse) and solid or semi-solid foods, allowing for any food or liquid including non-human milk and formula. ${ }^{50-53}$

The data collected on the Teleform will also be used to determine (1) the infant's age when a food other than human milk was first introduced (cessation of exclusive breast feeding) and (2) the infant's age when the dyad stopped breast feeding entirely (breastfeeding cessation). Taken together, this information can be used to identify each infant's duration of exclusive and complementary breast feeding.

In addition to infant feeding status, we will construct a dichotomous variable that describes infant feeding history. An infant feeding history can be constructed from the available data for each infant if (a) the date of exclusive and breastfeeding cessation are both recorded, (b) the infant had all age-appropriate vaccination visits and was still breast feeding at the last recorded visit (in this instance, the data are right censored) or (c) feeding data are recorded for each visit, regardless of feeding practice. Because we will have data on every infant, we will be able describe how those with missing feeding data or those whose data were not captured in the database differ from infants with feeding data recorded at each contact with the healthcare system. Table 4 presents the explanatory variables that we will use in these analyses. Explanatory variables will be developed using repository data from the mother and/or infant.

\section{Data analysis plan}

We will generate descriptive statistics to identify the percentage of infants in the cohort with feeding data at 2, 4 and 6-month vaccination visits and test whether data capture rates differ across time (research question 3). We will also test whether the percentage of infants with captured data differs by urban/rural status of the study site where they were vaccinated (research question 4). For each time point, we will calculate the socioeconomic distribution of infants across four categories: (1) infant has feeding data; (2) infant has vaccination recorded at a study site but does not have feeding data; (3) infant has a vaccination recorded at a non-study site and (4) infant does not have a vaccination recorded.

We will calculate the percentage of infant feeding data that are missing due to the infant receiving one or two vaccinations at a non-study site. Identifying the frequency with which this occurs will provide an estimate of the percentage of infants that could have complete infantfeeding data if Manitoba had a universal system that captured infant-feeding information.

Characteristics associated with having infant-feeding data captured in the database will be examined using logistic regression models for the 2, 4 and 6-month visits (research question 5). The outcome will be a dichotomous variable identifying whether or not a mother-infant dyad's infant-feeding information is captured in the database. Models will include the variables listed in table 4 . Each model will include a subcohort of age-appropriate infants; for example, analyses examining data collected at the 4-month vaccination visit will exclude anyone $\geq 4$ months of age. Results from these analyses will indicate whether mother-infant dyads captured by this strategy differ systematically from those who have missing data.

Finally, we will examine characteristics associated with whether or not we can construct an age-appropriate infant-feeding history using data held in the Manitoba Infant Feeding Database. The outcome variable will describe whether or not a complete infant-feeding history can be constructed based on available data. Explanatory variables will include those listed in table 4 .

\section{ETHICS AND DISSEMINATION}

\section{Ethical considerations}

The research team has completed the Tri-Council Course on Research Ethics. We have obtained approvals from the Health Research Ethics Board at the University of Manitoba, the Health Information Privacy Committee of Manitoba Health and the ethics committees in participating regional health authorities. Participation in the study is voluntary. Study participants are informed of the purpose of the study, potential risks associated with participation (compromise of data), their rights and obligations 


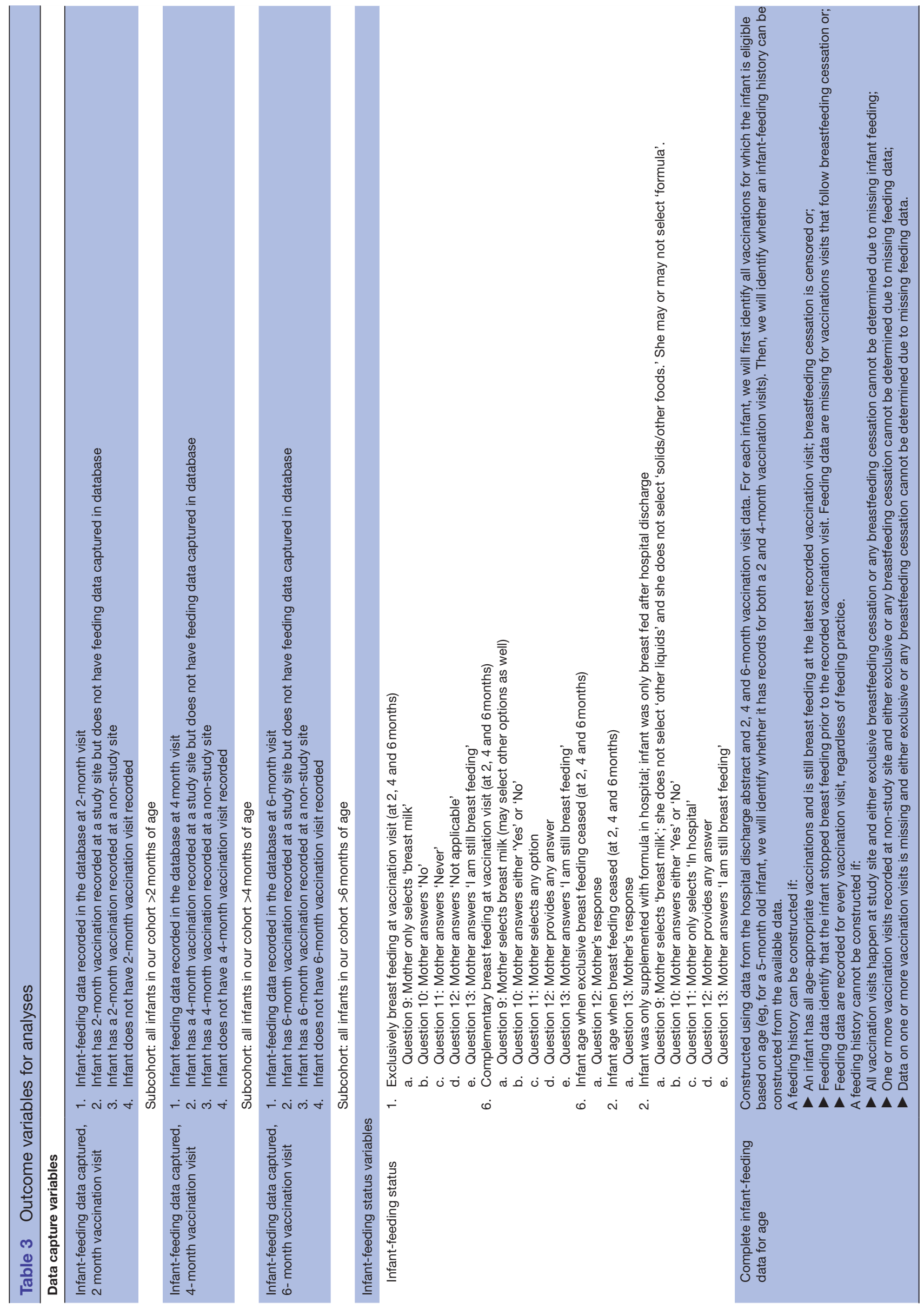


Table 4 Explanatory variables

\section{Parental characteristics}

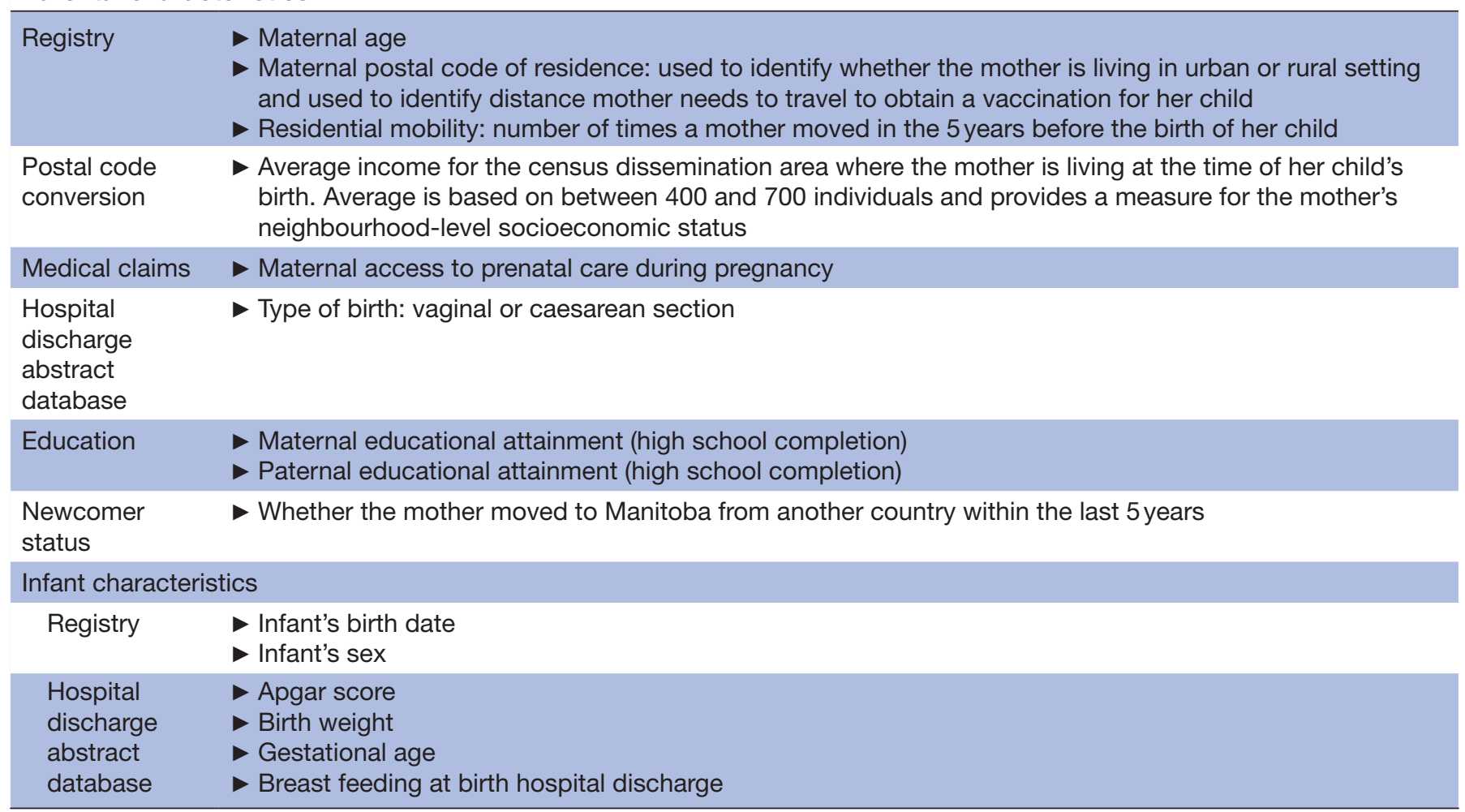

as participants and their ultimate right to withdraw at any point without negative consequences. We ask study participants for consent to link their data with the repository. Participants are informed that they will not be identifiable in any reports or publications. Informed consent is obtained from participants prior to data collection. Identified data are housed on a password-protected server in a secure data environment at the research office. The data are sent to Manitoba Health for deidentification and encryption. Only the data analysts have access to the deidentified data. Analyses using the deidentified data will be conducted in the secure data environment at the Manitoba Centre for Health Policy.

\section{Integrated knowledge translation and dissemination of findings}

The research team has adopted an integrative knowledge translation approach. In addition to academic researchers, the broader team comprises an interdisciplinary group of stakeholders from government departments, public health offices and regional health authorities. Over a 6-month prefunding planning period, the team worked together to develop a research plan and to secure peer-reviewed funding through a Research Manitoba New Investigator Operating Grant. While the core research team leads the study, the stakeholders are serving as advisory group members to ensure that findings can be applied to the population-based infant-feeding data collection strategy. The advisory group also strategises with the core research team on methods for disseminating findings to healthcare workers and other stakeholders in and outside of Manitoba.

Even at this early stage, there has been great interest in the study from stakeholders in government and public health. To date, we have presented the research plan and preliminary findings to public health officers in each regional health authority active in the study, and we have participated in two provincial meetings on breastfeeding practices. We have also widely disseminated the study aims and early findings in the academic community at the University of Manitoba. Near the end of the funding period, the team will host a province-wide workshop that will bring together public health nurses, clinic staff members and stakeholders to discuss the study findings and experiences with implementing the data collection mechanism. Two advisory group members are actively involved with the Breastfeeding Committee for Canada and will arrange for webinars to disseminate findings through this organisation. Findings will be presented at national and/or international conference(s) and will be submitted for peer-review publication to inform further research around infant-feeding data collection and provide evidence for building new population-based data collection systems.

Author affiliations

${ }^{1}$ Department of Community Health Sciences, Max Rady College of Medicine, Rady Faculty of Health Sciences, Universityof Manitoba, Winnipeg, Manitoba, Canada 
${ }^{2}$ Manitoba Centre for Health Policy, University of Manitoba, Winnipeg, Manitoba, Canada

${ }^{3}$ Department of Pediatrics and Child Health, Max Rady College of Medicine, Rady Faculty of Health Sciences, Universityof Manitoba, Winnipeg, Manitoba, Canada ${ }^{4}$ Injury Prevention and Child Health, Public Health Program, Winnipeg Regional Health Authority, Winnipeg, Manitoba, Canada

${ }^{5}$ Academic General Pediatrics, Division of General Pediatrics and Adolescent Health, University of Minnesota, Minneapolis, Minnesota, USA

${ }^{6}$ College of Nursing, Rady Faculty of Health Sciences, University of Manitoba, Winnipeg, Manitoba, Canada

${ }^{7}$ Population \& Public Health, Winnipeg Regional Health Authority, Winnipeg, Manitoba, Canada

${ }^{8}$ Department of Family Medicine, Max Rady College of Medicine, Rady Faculty of Health Sciences, University of Manitoba, Winnipeg, Manitoba, Canada

${ }^{9}$ Field Services Training Unit, Health Security Infrastructure Branch, Public Health Agency of Canada, Ottawa, Ontario, Canada

${ }^{10}$ Department of Public Health, Northern Health Region, Thompson, Manitoba, Canada

${ }^{11}$ Department of Surveillance and Epidemiology, Winnipeg Regional Health Authority, Winnipeg, Manitoba, Canada

Acknowledgements This study was part of a program of research conducted by the Manitoba Infant Feeding Database Development Team. The authors thank the clinic staff and public health nurses who collaborated with us on this project. The authors express their gratitude to the Developmental Origins of Chronic Disease in Children Network (DEVOTION) and the Lawson Foundation for their partnership. The authors also acknowledge the Manitoba Centre for Health Policy (MCHP) for use of the data in the Population Health Research Data Repository under project (HIPC No. 2014/2015-37). Data used in this study are from the Population Health Research Data Repository and were derived from data provided by Manitoba Health, Seniors and Active Living. The results and conclusions are those of the authors and no official endorsement by MCHP, Manitoba Health, Seniors and Active Living is intended or should be inferred.

Collaborators The Manitoba Infant Feeding Database Development Team: Joanne Chateau, Lawrence Elliott, Darlene Girard, Janet Grabowski, Christopher Green, Maureen Heaman, Alan Katz, Lisa Labine, Lorraine Larocque, Janice Loe, Eunice Lunsted, Teresa Mayer, Nathan C Nickel, Pam Noseworthy, Julia Paul, Carolyn Perchuk, Dawn Ridd, Elske Hildes Ripstein, Linda Romphf, Rob Santos, Geert t'Jong, Lynne Warda.

Contributors The study was conceived by NCN, the principal investigator on the original funded grant. NCN, LW, MH, AK and CG participated in designing the study and were listed as collaborators on the grant. NCN, JC and LW were involved in recruiting participating study sites, and NCN and JC are working with study sites on data collection processes. JC and JP are involved in data cleaning and verification. NCN, LK and JEE drafted the manuscript. All authors contributed to critically revising the manuscript for important intellectual content, gave their final approval and agreed to be accountable for all aspects of the work, and they will participate in future interpretation of the data and drafting of further manuscripts arising from this work.

Funding This work was supported by a New Investigator Operating Grant from Research Manitoba (Formerly Manitoba Health Research Council) - New Investigator Operating Grant Number 796. It is part of the Developmental Origins of Chronic Disease in Children Network (DEVOTION) and was supported in part by the Lawson Foundation (GRT2015-6).

Competing interests None declared.

Ethics approval Health Ethics Research Board at the University of Manitoba.

Provenance and peer review Not commissioned; externally peer reviewed.

Open Access This is an Open Access article distributed in accordance with the Creative Commons Attribution Non Commercial (CC BY-NC 4.0) license, which permits others to distribute, remix, adapt, build upon this work non-commercially, and license their derivative works on different terms, provided the original work is properly cited and the use is non-commercial. See: http://creativecommons.org/ licenses/by-nc/4.0/

(C) Article author(s) (or their employer(s) unless otherwise stated in the text of the article) 2017. All rights reserved. No commercial use is permitted unless otherwise expressly granted.

\section{REFERENCES}

1. Kramer MS, Kakuma R. Optimal duration of exclusive breastfeeding. Cochrane Database Syst Rev 2012;554:CD003517.

2. Ip S, Chung M, Raman G, et al. Breastfeeding and maternal and infant health outcomes in developed countries. 2007. http://www. ncbi.nlm.nih.gov/pubmed/17764214

3. Victora CG, Bahl R, Barros AJ, et al. Breastfeeding in the 21st century: epidemiology, mechanisms, and lifelong effect. Lancet 2016;387:475-90.

4. Stuebe AM, Willett WC, Xue F, et al. Lactation and incidence of premenopausal breast cancer: a longitudinal study. Arch Intern Med 2009;169:1364-71.

5. Stuebe AM, Schwarz EB, Grewen K, et al. Duration of lactation and incidence of maternal hypertension: a longitudinal cohort study. Am J Epidemiol 2011;174:1147-58.

6. Stuebe AM, Schwarz EB. The risks and benefits of infant feeding practices for women and their children. J Perinatol 2010;30:155-62.

7. Schwarz EB, McClure CK, Tepper PG, et al. Lactation and maternal measures of subclinical cardiovascular disease. Obstet Gynecol 2010;115:41-8.

8. UNICEF. Breastfeeding and complementary feeding Nutrition. UNICEF, 2015. https://www.unicef.org/nutrition/index_breastfeeding. html (accessed 5 Feb 2017).

9. World Health Organization (WHO). Infant and young child feeding: model chapter for textbooks for medical students and allied health professionals. Geneva, 2009:1-112.

10. Health CanadaCanadian Paediatric SocietyDietitians of CanadaBreastfeeding Committee for Canada. Nutrition for healthy term infants: recommendations from birth to six months. Can J Diet Pract Res 2012;73:204.

11. Eidelman A, Schanler R. American academy of pediatrics section on breastfeeding policy statement. Breastfeeding and the use of human milk. Pediatrics 2012;129:e827-41.

12. Eidelman Al. Breastfeeding and the use of human milk: an analysis of the American Academy of Pediatrics 2012 Breastfeeding Policy Statement. Breastfeed Med 2012;7:323-4.

13. Nickel NC, Martens PJ, Chateau D, et al. Have we left some behind? Trends in socio-economic inequalities in breastfeeding initiation: A population-based epidemiological surveillance study. Can J Public Heal Rev Can santé publique 2014:105.

14. Jones KM, Power ML, Queenan JT, et al. Racial and ethnic disparities in breastfeeding. Breastfeed Med 2015;10:186-96.

15. Dubois L, Girard M. Social determinants of initiation, duration and exclusivity of breastfeeding at the population level: The results of the Longitudinal Study of Child Development in Québec (ELDEQ 1998-2002). Can J Public Heal Rev Can santé publique 2003;94:300-5.

16. Chalmers B, Levitt $C$, Heaman $M$, et al. Breastfeeding rates and hospital breastfeeding practices in Canada: a national survey of women. Birth 2009;36:122-32.

17. US) $O$ of the SG, (US) $C$ for DC and P, (US) O on WH. The Surgeon General's Call to Action to Support Breastfeeding. US: Office of the Surgeon General, 2011. http://www.ncbi.nlm.nih.gov/pubmed/ 21452448 (accessed 29 May 2017).

18. Government of Canada PHA of C. Breastfeeding \& infant nutrition childhood and adolescence - public health agency of Canada. http:// www.phac-aspc.gc.ca/hp-ps/dca-dea/stages-etapes/childhoodenfance_0-2/nutrition/index-eng.php (accessed 29 May 2017).

19. Chapman DJ, Pérez-Escamilla R. US national breastfeeding monitoring and surveillance: current status and recommendations. $J$ Hum Lact 2009;25:139-50.

20. Leung BM, Giesbrecht GF, Letourneau N, et al. Perinatal nutrition in maternal mental health and child development: Birth of a pregnancy cohort. Early Hum Dev 2016;93:1-7.

21. Pani P, Carletti $C$, Knowles $A$, et al. Patterns of nutrients' intake at six months in the northeast of Italy: a cohort study. BMC Pediatr 2014;14:127.

22. Jones G, Steketee RW, Black RE, et al. How many child deaths can we prevent this year? Lancet 2003;362:65-71.

23. Nickel NC, Chateau DG, Martens PJ, et al. Data resource profile: Pathways to Health and Social Equity for Children (PATHS Equity for Children). Int J Epidemiol 2014;43:1438-49.

24. Roos LL, Brownell M, Lix L, et al. From health research to social research: privacy, methods, approaches. Soc Sci Med 2008:66:117-29.

25. Jutte DP, Roos LL, Brownell MD. Administrative record linkage as a tool for public health research. Annu Rev Public Health 2011;32:91-108.

26. Roos LL, Nicol JP, Cageorge SM. Using administrative data for longitudinal research: comparisons with primary data collection. J Chronic Dis 1987;40:41-9. 
27. Roos LL, Nickel NC, Romano PS, et al. Administrative Databases. In: Wiley StatsRef: Statistics Reference Online. Chichester,UK: John Wiley \& Sons, Ltd, 2015:1-17.

28. Roos LL, Nicol JP. Building individual histories with registries. A case study. Med Care 1983;21:955-69. http://journals.Iww.com.uml.idm. oclc.org/lww-medicalcare/Abstract/1983/10000/Building_Individual_ Histories_With_Registries_A.2.aspx

29. Ajetunmobi O, Whyte B, Chalmers J, et al. Informing the 'early years' agenda in Scotland: understanding infant feeding patterns using linked datasets. J Epidemiol Community Health 2014;68:83-92.

30. Busck-Rasmussen M, Villadsen SF, Norsker FN, et al. Breastfeeding practices in relation to country of origin among women living in Denmark: a population-based study. Matern Child Health $J$ 2014;18:2479-88.

31. Halvorsen MK, Langeland E, Almenning G, et al. Breastfeeding surveyed using routine data. Tidsskr Nor Laegeforen 2015;135:236-41.

32. Whaley SE, Koleilat M, Jiang L. WIC infant food package issuance data are a valid measure of infant feeding practices. $J$ Hum Lact 2012;28:134-8.

33. Martens PJ, Shafer LA, Dean HJ, et al. Breastfeeding initiation associated with reduced incidence of diabetes in mothers and offspring. Obstet Gynecol 2016;128:1095-104.

34. Manitoba centre for health policy university of manitoba. Manitoba Population Research Data Repository. 2017. http://www.umanitoba. $\mathrm{ca} /$ faculties/health sciences/medicine/units/chs/departmental units/ mchp/resources/repository/index.html (accessed 10 May 2017).

35. Manitoba centre for health policy university of manitoba. Manitoba Centre for Health Policy. 2017. http://umanitoba.ca/faculties/health_ sciences/medicine/units/chs/departmental_units/mchp/ (accessed 10 May 2017)

36. Martens PJ, Chateau DG, Burland EM, et al. The effect of neighborhood socioeconomic status on education and health outcomes for children living in social housing. Am J Public Health 2014;104:2103-13

37. Brownell MD, Chartier MJ, Nickel NC, et al. Unconditional prenatal income supplement and birth outcomes. Pediatrics 2016;137:e20152992.

38. Wall-Wieler E, Roos LL, Nickel NC. Teenage pregnancy: the impact of maternal adolescent childbearing and older sister's teenage pregnancy on a younger sister. BMC Pregnancy Childbirth 2016;16:120.

39. Randall JR, Chateau D, Smith M, et al. An early intervention for psychosis and its effect on criminal accusations and suicidal behaviour using a matched-cohort design. Schizophr Res 2016;176:307-11.

40. Shaw SY, Metge C, Taylor C, et al. Teen clinics: missing the mark? Comparing pregnancy and sexually transmitted infections rates among enrolled and non-enrolled adolescents. Int $J$ Equity Health 2016;15:95

41. Isaac MR, Chartier M, Brownell M, et al. Can opportunities be enhanced for vaccinating children in home visiting programs? A population-based cohort study. BMC Public Health 2015;15:620.

42. OpenText TeleForm. http://www.opentext.com/what-we-do/ products/customer-experience-management/customer- communications-management/opentext-teleform (accessed 29 Aug 2017).

43. Jenkins TM, Wilson Boyce T, Akers R, et al. Evaluation of a teleformbased data collection system: a multi-center obesity research case study. Comput Biol Med 2014;49:15-18.

44. NIH National Cancer Institute. Diet history questionnaire: canadian Version. https://epi.grants.cancer.gov/DHQ/forms/canadian/ (accessed 5 Sep 2017).

45. Pike I, McDonald RJ, Piedt S, et al. Developing injury indicators for first nations and inuit children and youth in Canada: a modified delph approach. Chronic Dis Inj Can 2014;34:203-9. https://www.canada. $\mathrm{ca} / \mathrm{en} /$ public-health/services/reports-publications/health-promotionchronic-disease-prevention-canada-research-policy-practice/vol-34no-4-2014/developing-injury-indicators-first-nations-inuit-childrenyouth-canada-modified-delphi-approa

46. Winnipeg regional health authority. HPECD Database User Manual, 2016. http://www.wrha.mb.ca/extranet/publichealth/files/ HPECDData2016.pdf (accessed 5 Sep 2017).

47. Fein SB, Grummer-Strawn LM, Raju TN. Infant feeding and care practices in the United States: results from the Infant Feeding Practices Study II. Pediatrics 2008:122:S25-S27.

48. Bonuck KA, Lischewski J, Brittner M. Clinical translational research hits the road: RCT of breastfeeding promotion interventions in routine prenatal care. Contemp Clin Trials 2009;30:419-26.

49. Fein SB, Labiner-Wolfe J, Shealy KR, et al. Infant Feeding Practices Study II: study methods. Pediatrics 2008;122:S28-S35.

50. WHO. The World Health Organization's infant feeding recommendation WHO published online First, 2015. http://www. who. int/nutrition/topics/infantfeeding_recommendation/en/ (accessed 29 Jul 2017)

51. WHO, Profiles C. WHO: Indicators for assessing infant and young child feeding practices. Young 2010;2007:1-19.

52. Labbok MH, Starling A. Definitions of breastfeeding: call for the development and use of consistent definitions in research and peerreviewed literature. Breastfeed Med 2012;7:397-402.

53. Labbok M, Krasovec K. Toward consistency in breastfeeding definitions. Stud Fam Plann 1990;21:226-30.

54. Li R, Scanlon KS, Serdula MK. The validity and reliability of maternal recall of breastfeeding practice. Nutr Rev 2005;63:103-10.

55. Bland RM, Rollins NC, Solarsh G, et al. Maternal recall of exclusive breast feeding duration. Arch Dis Child 2003;88:778-83.

56. Aarts C, Kylberg E, Hörnell A, et al. How exclusive is exclusive breastfeeding? A comparison of data since birth with current status data. Int J Epidemiol 2000;29:1041-6 http://www.ncbi.nlm.nih.gov/ pubmed/11101545

57. Binns CW, Fraser ML, Lee AH, et al. Defining exclusive breastfeeding in Australia. J Paediatr Child Health 2009;45:174-80.

58. Greiner T. Exclusive breastfeeding: measurement and indicators. Int Breastfeed J 2014:9:18.

59. Hector DJ. Complexities and subtleties in the measurement and reporting of breastfeeding practices.

60. Habtemariam Fenta E, Yirgu R, Shikur B, et al. A single $24 \mathrm{~h}$ recall overestimates exclusive breastfeeding practices among infants aged less than six months in rural Ethiopia. 